\title{
Speckle-Tracking of Left Ventricle by Transesophageal Echocardiography in a Patient with COVID-19
}

\author{
Jeanette Wehit ${ }^{1}$, Fernando Sosa ${ }^{1}$, Pablo Merlo ${ }^{2}$, Javier Roberti ${ }^{3}$, and Javier Osatnik ${ }^{1}$ \\ ${ }^{1}$ Hospital Aleman \\ ${ }^{2}$ Hospital General de Agudos Bernardino Rivadavia \\ ${ }^{3}$ Affiliation not available
}

June 3, 2020

\begin{abstract}
A 68-year-old male presented with flu-like symptoms, fatigue, history of obesity, hypertension, type II diabetes and chronic smoking. Chest radiography revealed right basal opacity consisting of infiltrate. With respiratory failure, orotracheal intubation and mechanical ventilation were performed. Patient presented gas exchange alteration. Real-time PCR detected SARS-CoV-2. Treatment with liponavir/ritonavir and hydroxychloroquine was started. Because of poor acoustic window, speckle-tracking transoesophageal echocardiography (TEE) was performed, detecting deterioration in global longitudinal strain. On day 15 , the patient suffered bacteraemic sepsis at endovascular focus with Serratia marcescens and multiorgan failure. TEE-guided haemodynamic monitoring was repeated showing global longitudinal strain improvement.
\end{abstract}

\section{Introduction}

The novel coronavirus disease (COVID-19) has been spreading exponentially in most countries around the world. Its clinical course is characterized by respiratory tract symptoms. ${ }^{1}$ However, COVID-19 also affects multiple organs and acute myocarditis has been described as an associated complication. ${ }^{2}$ Haemodynamic monitoring is important in the recovery process. Bedside transthoracic echocardiography (TTE) may be insufficient due to deficient acoustic window or suboptimal views when using positive end-expiratory pressure in mechanically ventilated patients. ${ }^{3-6}$ Strain imaging using speckle-tracking TEE could play a crucial role because of its greater sensitivity for the early diagnosis of myocarditis associated to COVID-19 in critically ill patients. We present a patient with COVID-19 whose myocardial deformation was detected using myocardial strain speckle-tracking by TEE.

\section{Case}

A 68-year-old male presented to the emergency department with a complaint of flu-like symptoms for the previous ten days and fatigue that had worsen in the previous hours. The patient had a history of obesity (BMI $33 \mathrm{~kg} / \mathrm{m}^{2}$ ), hypertension (treated with amlodipine $10 \mathrm{mg}$ /day and enalapril $10 \mathrm{mg} /$ day), type II diabetes (treated with empagliflozine), and chronic smoking (40 pack-year). An echocardiogram in September 2019 had shown normal biventricular size and function. When admitted to intensive care unit with acute respiratory failure, the patient presented an APACHE II of 8, a SAPS II of 18 and a SOFA of 3.

The patient required oxygen therapy at $2 \mathrm{~L} / \mathrm{min}$, with adequate ventilatory mechanics, body temperature of $38^{\circ} \mathrm{C}$; he was haemodynamically stable and lucid. Laboratory results showed metabolic acidosis and respiratory alkalosis without hyperlactacidemia, creatinine clearance MDRD $62 \mathrm{~mL} / \mathrm{min}$, preserved leukocyte formula, and a normal hepatogram. Markers were LDH $198 \mathrm{UI} / \mathrm{l}$; troponin T $16 \mathrm{pg} / \mathrm{mL}$, ferritine $723 \mathrm{ng} / \mathrm{mL}$, $\mathrm{BnP} 370 \mathrm{pg} / \mathrm{mL}$; Dimer D300. Chest radiography revealed right basal opacity consisting of an infiltrate. 
Respiratory sepsis with suspicion of SARS-COV2 was deemed as likely; therefore, empirical therapy with ampicillin/sulbactam was started. On day 3 , the patient showed a more severe hypoxemia which required orotracheal intubation and mechanical ventilation. The patient presented with alteration of gas exchange $(\mathrm{PaO} 2 / \mathrm{FiO} 2167 \mathrm{mmHg})$; so, anaesthesia was maintained with remifentanil $(15 \mathrm{mcg} / \mathrm{Kg} / \mathrm{h})$ and propofol $(1.42 \mathrm{mg} / \mathrm{Kg} / \mathrm{h}$ ), RASS target of -5 ; in addition, neuromuscular blockers (atracurium $1.1 \mathrm{mg} / \mathrm{Kg} / \mathrm{h}$ ) were indicated. Protective mechanical ventilation was performed with a tidal volume of $6 \mathrm{~mL} / \mathrm{kg}$ of ideal body weight with the following lung mechanic: volume-controlled ventilation $530 \mathrm{~mL}$, positive end-expiratory pressure of $10 \mathrm{~cm} \mathrm{H} 2 \mathrm{O}, \mathrm{RR}$ of $20 \mathrm{rpm}, 40 \% \mathrm{FiO}_{2}$; plateau pressure of $17 \mathrm{~cm} \mathrm{H} 2 \mathrm{O}$, driving pressure of $7 \mathrm{~cm} \mathrm{H} 20$, static compliance $75 \mathrm{~mL} \mathrm{~cm} \mathrm{H2O}$. Respiratory filmarray panel detected Coronavirus NL63 and real-time reverse transcriptase-polymerase chain reaction assay detected SARS-CoV-2. Treatment with liponavir/ritonavir and hydroxychloroquine was started. Three days later, because of prolonged QTc interval, treatment with antimalarials was discontinued. Due to persistent gas exchange alteration $(\mathrm{PaO} 2 / \mathrm{FiO} 2<150 \mathrm{mmHg})$, the prone position was performed five times with subsequent improvement of $\mathrm{PaO} 2 / \mathrm{FiO} 2$ ratio, keeping lung mechanics.

As a result of poor acoustic window, guided monitoring by TEE was performed on day 5, using an CX50 Philips Ultrasound (X7-2t) fitted with a multiplane 2-7MHz TEE transducer, following a standard procedure (Figure 1A), detecting deterioration in global longitudinal strain. Table 1 shows speckle-tracking analysis. Subsequently, on day 15, the patient suffered bacteraemic sepsis at endovascular focus withSerratia marcescens; therefore, treatment with imipenem depending on sensibility was started. The patient presented multiorgan failure, norepinephrine $(0.2 \mathrm{mcg} / \mathrm{Kg} / \mathrm{min})$ was administered; respiratory values were $\mathrm{PaO} 2 / \mathrm{FiO} 2$ $<150 \mathrm{mmHg}$ in treatment with protective mechanical ventilation, neuromuscular blocking, and prone position. In addition, haemodialysis was started. TEE-guided haemodynamic monitoring was performed on day 16 (Figure 1B). On day 22, the patient was still in the intensive care unit and has shown two negative tests for COVID-19. Written consent was obtained.

\section{Discussion}

Patients with COVID-19 infection and associated myocardial injury may have an increased mortality compared with patients with normal troponin levels. ${ }^{1,2}$ Although the diagnosis of myocarditis still depends on the increase of troponin $t$, new cardiac image techniques could show ventricular failure. ${ }^{6-8}$ In our case, a pronounced deterioration in both global and segmental longitudinal strain was observed, suggestive of acute myocarditis despite the only slight increase in cardiac troponin. The speckle-tracking TEE was repeated, and a notable improvement was seen in the global longitudinal strain values without significant changes in cardiac troponin. The need for a good quality image by common two-dimensional ultrasound imagining was met by speckle-tracking TEE, a strategy not widely used.

Speckle-tracking echocardiography works as a "digital biopsy" and it could become an essential diagnostic tool for myocarditis and septic cardiomyopathy. ${ }^{9}$ Understanding atypical presentations and imaging findings contribute to prompt diagnosis of COVID-19 induced myocarditis.

Table 1. Left ventricle speckle-tracking analysis

\begin{tabular}{lll}
\hline Segments & Deformation (\%) TEE (Day & Deformation (\%) TEE (Day \\
& $\mathbf{5})$ & $\mathbf{1 6})$ \\
Segment 13 & $-18 \%$ & $-27 \%$ \\
Segment 14 & $-9 \%$ & $-29 \%$ \\
Segment 15 & $-12 \%$ & $-26 \%$ \\
Segment 16 & $-10 \%$ & $-29 \%$ \\
Segment 17 & $-12 \%$ & $-28 \%$ \\
Mean apical Strain \% & $-12.2 \%$ & $-27.8 \%$ \\
Segment 8 & $-11.7 \%$ & $-23 \%$ \\
Segment 9 & $-12 \%$ & $-18 \%$ \\
Segment 11 & $-18 \%$ & $-17 \%$
\end{tabular}


Segment $12 \quad-8 \% \quad-24 \%$

Mean Medial Strain \% $\quad-12.4 \% \quad-20.5 \%$

Abbreviation: TEE, transoesophageal echocardiography

Author contributions

Concept/design: JW, FS; Data analysis/interpretation JW, FS, PM, JO; Drafting article, JW, PM, JR; Critical revision of article, JR, JO; Approval of article, JW, FS, PM, JR, JO; Data collection, JW, FS

\section{References}

1. Weiss P, Murdoch DR. Clinical course and mortality risk of severe COVID-19. The Lancet. 2020;395(10229):1014-1015.

2. Guzik TJ, Mohiddin SA, Dimarco A, et al. COVID-19 and the cardiovascular system: implications for risk assessment, diagnosis, and treatment options. Cardiovasc Res. 2020.

3. Shahul S, Gulati G, Hacker MR, et al. Detection of Myocardial Dysfunction in Septic Shock: A SpeckleTracking Echocardiography Study. Anesth Analg. 2015;121(6):1547-1554.

4. Dalla K, Hallman C, Bech-Hanssen O, Haney M, Ricksten SE. Strain echocardiography identifies impaired longitudinal systolic function in patients with septic shock and preserved ejection fraction.Cardiovasc Ultrasound. 2015;13:30.

5. Sanfilippo F, Corredor C, Fletcher N, et al. Left ventricular systolic function evaluated by strain echocardiography and relationship with mortality in patients with severe sepsis or septic shock: a systematic review and meta-analysis. Crit Care. 2018;22(1):183.

6. Hensel KO, Wilke L, Heusch A. Transthoracic Speckle Tracking Echocardiography for the Quantitative Assessment of Left Ventricular Myocardial Deformation. J Vis Exp. 2016(116).

7. Kukucka M, Nasseri B, Tscherkaschin A, Mladenow A, Kuppe H, Habazettl H. The feasibility of speckle tracking for intraoperative assessment of regional myocardial function by transesophageal echocardiography. $J$ Cardiothorac Vasc Anesth. 2009;23(4):462-467.

8. Sutherland GR, Di Salvo G, Claus P, D'Hooge J, Bijnens B. Strain and strain rate imaging: a new clinical approach to quantifying regional myocardial function. J Am Soc Echocardiogr. 2004;17(7):788-802.

9. Shah SJ. 20th Annual Feigenbaum Lecture: Echocardiography for Precision Medicine-Digital Biopsy to Deconstruct Biology. J Am Soc Echocardiogr. 2019;32(11):1379-1395 e1372.

\section{Hosted file}

Figure 1.docx available at https://authorea.com/users/329269/articles/456289-speckletracking-of-left-ventricle-by-transesophageal-echocardiography-in-a-patient-with-covid19 